\title{
EL COLEGIO DE PROFESIONALES EN SOCIOLOGÍA DE COSTA RICA Y SU IMPACTO EN LA DEMOCRACIA COSTARRICENSE ${ }^{I}$
}

\section{THE ASSOCIATION OF PROFESSIONALS IN SOCIOLOGY OF COSTA RICA AND ITS IMPACT ON DEMOCRACY IN COSTA RICA}

\author{
Asdrúbal Alvarado Vargas*
}

\begin{abstract}
RESUMEN
El artículo analiza el papel que el Estado le asigna al Colegio de Profesionales en Sociología de Costa Rica (CPSCR), al ser creado por Ley de la República como una organización privada, con fines públicos, característica que le confiere una responsabilidad en el fortalecimiento de la democracia distributiva, lo que implica la protección de los derechos de las y los ciudadanos por parte del Estado, al tener el deber de garantizar la honestidad e idoneidad de los servicios profesionales que se brindan al público en el campo de la Sociología.
\end{abstract}

PALABRAS CLAVE: COSTA RICA * SOCIOLOGÍA * DEMOCRACIA * MERCADO DE TRABAJO * COLEGIOS PROFESIONALES

\section{ABSTRACT}

This article discussed the role that the State assigns to the Association of Professionals in Sociology of Costa Rica (CPSCR), which was created by Act of the Republic as a private organization, with public purposes, characteristic that confers a responsibility in distributive democracy strengthening, which implies the protection of the rights of citizens by the State, having the duty to guarantee the honesty and suitability of the professional services offered to the public in the field of the sociology.

KEYWORDS: COSTA RICA * SOCIOLOGY * DEMOCRACY $*$ LABOUR MARKET * PROFESSIONALS ASSOCIATIONS

Escuela de Sociología de la Universidad de Costa Rica (UCR).

asdrubal.alvarado@ucr.ac.cr

El presente trabajo se benefició con los aportes y sugerencias de estimables colegas, quienes tuvieron la gentileza de leerlo, sugerir y aportar observaciones que lo enriquecieron y fortalecieron. Gracias al Dr. Daniel Camacho Monge, sociólogo y abogado; a la socióloga Olga Prieto Cruz, a la socióloga y abogada Irina Sibaja López y a la socióloga Sylvia Marchena Villalobos. Sin duda, sus aportes fueron muy importantes en la elaboración de este artículo. 


\section{INTRODUCCIÓN}

Durante décadas, los sociólogos y las sociólogas costarricenses aspiraron a organizarse en el marco de un Colegio Profesional. La ausencia de una organización aglutinadora, protectora y certificadora, hizo tener una imagen de profesionales de segunda clase. Se sentía el vacío de una entidad de respaldo que liderara y promoviera la creación de espacios de encuentro para el intercambio de ideas y sentimientos en los campos de la ciencia, los temas de interés común y el solaz. Las iniciativas y esfuerzos fructificaron en el año 2011, con la creación del Colegio de Profesionales en Sociología de Costa Rica, sancionado mediante Ley nro. 8974.

El presente artículo ofrece una breve descripción sobre el proceso fundacional y de institucionalización de la Sociología en Costa Rica, como antecedente al abordaje, análisis y argumentación del significado de una aspiración, de una lucha de más de tres décadas; la creación del Colegio de Profesionales en Sociología de Costa Rica, al que se seguirá denominando Colegio.

Interesa, muy especialmente, destacar el rol esencial que el Estado costarricense le asigna a esta organización profesional mediante Ley de la República, al ser creada con fines públicos, característica que le otorga un importante papel en el fortalecimiento de la democracia.

Para fundamentar esto, se parte del concepto republicano de democracia, la democracia representativa, que invoca a la elección de los titulares de los cargos en los poderes del Estado. Concepto que a su vez, se articula con los contenidos de la democracia participativa, que es la que permite y promueve la influencia de los ciudadanos en las decisiones políticas del Estado. Ambos conceptos conjugan sus contenidos y se expresan en la democracia distributiva, que en el caso analizado, implica la protección de los derechos ciudadanos por parte del Estado, lo cual se expresa y materializa en el capítulo de la Ley sobre los fines, objetivos y propósitos del Colegio, que se analizarán más adelante.

Lo anterior significa que el Estado, por medio de la Ley de Creación, encomienda al Colegio, la protección de los ciudadanos y le confiere la responsabilidad de garantizar la honestidad e idoneidad de los servicios profesionales que se brindan al público en el campo de la Sociología. Por este motivo, uno de los objetivos es fundamentar $y$ posicionar la importancia de las organizaciones de profesionales en Sociología en los procesos de fortalecimiento de la democracia.

\section{ORIGEN, RETOS Y PERSPECTIVAS DE LA SOCIOLOGIA EN COSTA RICA}

\subsection{PROCESO FUNDACIONAL E INSTITUCIONALIZACIÓN DE LA SOCIOLOGÍA EN COSTA RICA}

La Sociología en Costa Rica ha recorrido un importante camino que merece ser precisado brevemente. La perspectiva sociológica no es una cuestión nueva en esta academia, ha estado presente en el análisis y la interpretación de los procesos socioeconómicos y sociopolíticos de la realidad nacional e internacional desde los años 40 del siglo pasado, cuando se creó la Universidad de Costa Rica. Su proceso de desarrollo se ha visto acompañado con la graduación de cientos de profesionales, egresados de las dos escuelas de Sociología que existen en Costa Rica. El ejercicio profesional de estos, en una variada cantidad de instituciones públicas, organizaciones no gubernamentales nacionales e internacionales, evidencia un proceso de consolidación, diversificación y especialización del espacio laboral para la Sociología.

La enseñanza de la Sociología en Costa Rica, inicia con la elaboración y puesta en práctica de cursos que formaban parte de los planes de estudio de otras carreras. Por ejemplo, en la Escuela Normal Nacional, en la que se formaban profesores $y$ profesoras para la enseñanza primaria y secundaria en el Sistema Educativo del Ministerio de Educación Pública; en la Escuela de Pedagogía de la Universidad de Costa Rica desde 1941; en la Escuela de Ciencias Económicas y Sociales (1943), específicamente en la carrera de Servicio Social de la época y en la Escuela de Filosofía y Letras de la Universidad de Costa Rica. 
De acuerdo con el sociólogo Jorge Rovira Mas: “... la enseñanza de la Sociología en Costa Rica $y$ en la Universidad de Costa Rica es anterior a la introducción y a la difusión de los planteamientos que acompañaron al proyecto de la Sociología científica; de 1957 en adelante" (2000: 867).

Según este mismo autor, es con la reforma universitaria aprobada en 1955 y que entra en vigencia en 1957, que se empiezan a dar las modificaciones sustantivas en la enseñanza de la Sociología en el marco de los Estudios Generales de la Universidad de Costa Rica, como disciplina científica. En los años 60 del siglo pasado:

Se establecieron primero la Comisión para el estudio de las Ciencias del Hombre (1962), que pronto pasó a funcionar como Sección de Ciencias del Hombre, y un poco más tarde el Departamento de Ciencias del Hombre (1967), todas estas entidades en el interior de la entonces Facultad de Ciencias y Letras de la Universidad de Costa Rica. No hay duda que con estas instancias académicas se sentaron las bases fundamentales del proceso de institucionalización de la Sociología en nuestro país. Sólo entonces nuestra disciplina se convirtió no simplemente en un curso que los estudiantes debían o podían llevar, como parte de los Estudios Generales, dentro de sus respectivos planes de estudios, sino en una nueva opción profesional y académica para los universitarios. Sólo a partir de entonces es que se ha procurado desbrozar el arduo y aún hoy inconcluso camino de reconocimiento profesional y social para la Sociología como disciplina con perfil propio $y$ diferenciado en el ámbito nacional (Rovira, 2000: 824).

En el Departamento de Ciencias del Hombre, creado en 1967, se inició el primer plan de estudios de Bachillerato en Sociología y en 1970, empiezan a salir sus primeros graduados con un diploma universitario en Sociología, obtenido en Costa Rica.

Otro hecho importante en el proceso fundacional $y$ de institucionalización de la So- ciología en Costa Rica, fue la puesta en marcha del Programa de Licenciatura Centroamericana en Sociología en 1973, creado en el marco del mencionado Departamento de Ciencias del Hombre, con apoyo del Consejo Superior Universitario de Centro América (csuca). Su carácter regional motivó la formación de una considerable cantidad de profesionales de la región como sociólogos en Costa Rica. Asimismo, hay que mencionar la creación en 1979, del Programa Centroamericano de Maestría en Sociología, el cual cumplió en agosto de 2014, 35 años de existencia.

El Departamento de Ciencias del Hombre aglutinaba tres carreras: Antropología, Psicología y Sociología; en 1969 y 1970 empiezan a graduarse de Bachillerato, los primeros estudiantes de Sociología.

En 1977, estas tres carreras se separan y se crea la Escuela de Antropología y Sociología, cuyo primer Director fue el Dr. Eugenio Fonseca Tortós, considerado como el sociólogo de mayor influencia en el proceso fundacional $y$ de institucionalización de la Sociología científica en Costa Rica; esto es, en palabras de Jorge Rovira:

... la Sociología entendida con todo rigor como una ciencia social plenamente contemporánea, se funda $y$ da los primeros pasos en su proceso de institucionalización en Costa Rica a partir del momento en que comienza a enseñársela bajo una concepción acorde con los parámetros internacionales (de teoría, de métodos y técnicas) que la acreditan como una disciplina con rango científico, diferente a la Filosofía Social y a otras prácticas académicas o culturales que pudieran interesarse en el mismo objeto de comprensión $o$ análisis y que pudieran incluso haber pasado antes por Sociología. Pero este proceso de fundación y de institucionalización básica no concluye sino hasta que se crea una entidad orientada a la enseñanza de los que serán los oficiantes de la disciplina, entidad capaz igualmente de desarrollar la investigación científica dentro de su ámbito particular de conocimiento (2000: 832-833). 
En un primer momento, esa entidad fue la carrera de Sociología en el marco del Departamento de Ciencias del Hombre; en un segundo momento, fue la Escuela de Antropología y Sociología, la cual el 7 de enero de 2008, pasa a denominarse Escuela de Sociología, nombre que mantiene hasta la fecha y se crea la nueva Escuela de Antropología.

Cabe destacar que en 1974, se funda otra Escuela de Sociología en Costa Rica con sede en la Universidad Nacional, localizada en la cuidad de Heredia.

\subsection{PRESENCIA DE LA ESCUELA DE SOCIOLOGía DE LA UNIVERSIDAD DE COSTA RICA EN LA SOCIEDAD $^{2}$}

En este apartado se describe la contribución de la Sociología, desarrollada en la Universidad de Costa Rica y en sus instituciones predecesoras, al avance científico y al desarrollo social del país. Al decir avance científico, se está haciendo referencia tanto al conocimiento aplicado como al campo teórico, incluso en sus manifestaciones de mayor abstracción. Interesa centrar la atención sobre la influencia y la presencia de la Sociología en la sociedad.

Lo dicho está muy lejos de considerar la pertinencia del quehacer académico solamente con el parámetro de su utilidad práctica. Si la tiene, tanto mejor. Pero la reflexión y la investigación básica, fundamental y abstracta, son de gran importancia, ya no para las necesidades inmediatas, sino para el desarrollo de las potencialidades humanas y para el crecimiento cualitativo de la humanidad como tal.

Esto significa un rechazo de las tesis según las cuales, en el campo del quehacer científico, solo constituye contribución real lo que se traduce en utilidad práctica inmediata. Por lo anterior, al hacer referencia a los aportes de la Escuela de Sociología, se mencionarán tanto aquellos de utilidad inmediata como los más abstractos.

Es simbólico comenzar por el aporte de la piedra angular de la Escuela: sus estudiantes. El clímax de la tarea estudiantil es su Tesis o

2 Algunos contenidos de este apartado han sido tomados de Alvarado y Camacho, 2011.
Trabajo Final de Graduación. En la Escuela de Sociología, tanto en su carrera de Licenciatura como en la Maestría Centroamericana de Sociología, se ha producido un considerable número de trabajos de graduación de calidad, así como una considerable cantidad de profesionales con títulos de Bachillerato, Licenciatura y Maestría. A continuación se exponen algunos datos al respecto:

CUADRO 1

POBLACIÓN DE GRADUADOS EN LA CARRERA DE SOCIOLOGÍA

UNIVERSIDAD DE COSTA RICA 1974-2013

\begin{tabular}{cc}
\hline NIVEL PROFESIONAL & NÚMERO DE GRADUADOS \\
\hline Bachillerato & 850 \\
Licenciatura & 424 \\
\hline TOTAL & 1274 \\
\hline
\end{tabular}

Fuente: Elaboración propia con datos de la Oficina de Registro e Información (ORI) de la Universidad de Costa Rica, $2013^{3}$.

En la Universidad de Costa Rica, desde el año 1974 hasta el 2013, se han graduado como profesionales en Sociología, un total de 1274 personas. Históricamente, se han invertido grandes esfuerzos, en promover que los graduados de Bachillerato continúen y concluyan el plan de estudios con el título de Licenciatura. Lamentablemente, este objetivo ha sido difícil de alcanzar a plenitud, una significativa cantidad de estudiantes (alrededor del 50\%) obtienen el título de Bachillerato, pero no continúan o no concluyen con la obtención del título de Licenciatura.

Sin embargo, se puede considerar que la promoción de un promedio de 23 bachilleres y 12 licenciados(as) en Sociología por año, es un aporte apreciable en la formación académica de profesionales con capacidad analítica, explicativa y propositiva en la solución de los problemas societales.

$3 \quad$ Extraído del documento inédito: Propuesta de Reforma del Plan de Estudios de Bachillerato en Sociología. 
Algunas de las orientaciones temáticas más recientes de los Trabajos Finales de Graduación de los estudiantes de Licenciatura son: representaciones sociales, medios de comunicación, análisis del discurso, turismo rural, capital social, reconfiguración socio-productiva $y$ laboral, género $y$ trabajo sexual, desastres $y$ vulnerabilidad social, arte y construcción de la identidad costarricense, violencia simbólica en educación, entre otros.

Por otra parte, en la Maestría en Sociología, la cual tiene carácter centroamericano, se han producido 126 tesis desde 1982 hasta 2013. Esta Maestría es de muy alto nivel por la calificación y grados académicos de sus profesores, así como por el sistema de becas que ha permitido a una considerable cantidad de sus alumnos dedicar tiempo suficiente a sus estudios. $\mathrm{Al}$ igual que el Bachillerato y la Licenciatura, cuenta también con la riqueza de los recursos bibliográficos en materia de Ciencias Sociales de las diferentes bibliotecas de la Universidad, acceso a laboratorios de computación y se recibe la visita de conferenciantes extranjeros de alto nivel. Los trabajos de graduación son guiados y supervisados por tutores $y$ lectores quienes exigen mucha rigurosidad.

Una gran parte de los alumnos hacen estudios acerca de los países centroamericanos de los cuales provienen. Las investigaciones versan sobre temas rurales, laborales, políticos, sanitarios, estatales, comunitarios, geopolíticos, feministas, ideológicos, sindicales, militares entre otros.

En los trabajos de Sociología, es tradición elaborar un marco teórico acerca del tema, lo cual hace que cada uno de esos graduados ostente una formación teórica aceptable y a veces, notable. Eso quiere decir que egresan de la Universidad preparados para asumir tareas de profesionales en Sociología especializados en sus respectivos campos y con conocimientos teóricos actualizados. Las personas graduadas de la Escuela de Sociología se han insertado en el mercado laboral de diversas maneras. Sin embargo, hay que admitir que solo con el grado de Bachillerato universitario es difícil conseguir cargos como profesionales en esta disciplina. Pero en una exploración hecha hace algunos años, se encontró que a partir del grado de Licenciatura, todas las personas egresadas laboran en puestos afines con su profesión. En cambio, se encontraron graduados de Bachillerato en las ocupaciones más disímiles y alejadas del campo ${ }^{4}$.

José Carlos Chinchilla (1993) señala las actividades que desarrollaban las y los sociólogos hasta la década de los 90 del siglo pasado (no solo de la Universidad de Costa Rica, sino los graduados en todas las universidades) y las agrupa en cuatro conglomerados: investigador, catalizador (mediador operativo)-proyectista, director-coordinador $y$ docente.

Como investigadores, una gran parte se dedica a la investigación operativa para respaldar decisiones en los ámbitos público y privado. Además, se realizan investigaciones de tipo teórico. En labores catalizadoras, la función es facilitar las relaciones de grupos sociales dentro de ellos o con otros grupos. En su función de proyectistas, participan en proyectos concretos de desarrollo y en la función de dirección, se hacen cargo de conducir grupos de trabajo. En la función docente se contribuye al avance $y$ la reproducción de la disciplina. De esta manera, se trata de una amplia gama de tareas relacionadas directamente con el desarrollo social y en todas ellas el propósito es respaldar técnica y científicamente la toma de decisiones y las actividades prácticas. Esa participación permite anticiparse a los acontecimientos, prevenir la improvisación, utilizar los recursos con mayor eficiencia y eficacia, así como contribuir al mejor conocimiento de la sociedad. Se trata de una contribución efectiva al desarrollo humano.

La Escuela de Sociología de la Universidad de Costa Rica ha contribuido también de manera notable al desarrollo de la disciplina en el ámbito internacional, tanto a nivel centroamericano como latinoamericano. Esta escuela albergó la célebre Licenciatura Centroamericana de Sociología en la dramática época de las guerras civiles centroamericanas de finales del

4 Se trató de una exploración hecha dentro de un Trabajo Comunal Universitario por estudiantes dirigidos por el Dr. Daniel Camacho, cuyo respaldo documental se ha perdido. Pero ese hallazgo si se recuerda en forma clara y precisa. 
Siglo xx. De esa manera, suplió las carencias en la formación de científicos sociales que debido a los conflictos bélicos, sufrían los pueblos del istmo. Años después, cuando las condiciones políticas comenzaron a mejorar, los egresados de esa licenciatura ocuparon los cargos fundacionales $y$ directivos de los departamentos universitarios dedicados al desarrollo de las Ciencias Sociales en los países centroamericanos. Actualmente, aún se reconoce en esos países la importante contribución costarricense y específicamente, de la entonces Sección de Sociología del Departamento de Ciencias del Hombre.

Obras de algunos de los profesores-investigadores de la actual Escuela de Sociología, han tenido una influencia importante en el ámbito nacional, centroamericano y latinoamericano. No se mencionan concretamente para evitar involuntarias omisiones que podrían herir susceptibilidades. Sin embargo, es relevante recordar que algunas han sido premiadas, otras han sido publicadas por editoriales internacionales $y$ otras más han ejercido una reconocida influencia en el desarrollo de las Ciencias Sociales en el ámbito nacional e internacional.

La Escuela de Sociología fue la plataforma de lanzamiento del rescate de la Facultad Latinoamericana de Sociología (flacso). Esa importante institución latinoamericana sufrió un colapso al final de la década de los 70 , producto de algunos problemas internos, pero sobre todo, de las dictaduras del Cono Sur, estando a punto de desaparecer. A partir del Departamento de Sociología y del Instituto de Investigaciones Sociales, la Universidad de Costa Rica desplegó esfuerzos y recursos para el rescate de esa institución, lo cual fue reconocido por los gobiernos de los países latinoamericanos miembros de la Flacso, hasta el punto de que su Secretaría General fue trasladada a Costa Rica y aquí ha funcionado desde hace más de treinta años.

También en el ámbito internacional, el papel del entonces Departamento de Sociología fue importante en la fundación de la Asociación Centroamericana de Sociología (ACAS) en 1974, la cual sigue activa, incluso en el 2010 celebraba su xII congreso en Costa Rica. En 1974, también se realizó en la Universidad de Costa Rica el xi Congreso Latinoamericano de Sociología, muy recordado como el Congreso de la Diáspora, pues logró reunir a los más connotados sociólogos y sociólogas del continente, quienes acababan de escapar de las cruentas dictaduras que en los años inmediatamente anteriores, se instalaron en varios países latinoamericanos.

Actualmente, en la Escuela de Sociología se realizan importantes esfuerzos orientados a fortalecer y consolidar su presencia e influencia en la sociedad. Se continúan fortaleciendo proyectos importantes en el marco de la propuesta de las políticas, las cuales rigen las actividades sustantivas de la Universidad y que se orientan al logro de una adecuada relación UniversidadSociedad, mediante excelencia académica y una adecuada cobertura y equidad. Todo lo anterior con el fin de promover procesos de accesibilidad, permanencia y éxito académico de la población estudiantil; fortaleciendo las actividades docentes, de investigación y acción social como los pilares del desarrollo académico e incidencia en el desarrollo social. En esta línea, se han venido consolidando actividades de extensión docente y acción social, en procura de abrir espacios de participación para profesionales de otras disciplinas en cursos sobre temas que requieren enfoques interdisciplinarios.

En el caso de los proyectos y actividades de acción social propiamente dicho, en los últimos años se ha consolidado el trabajo en comunidad, realizado con grupos de líderes locales, mujeres, jóvenes y familias campesinas en localidades rurales de diferentes zonas costarricenses. También en los últimos años, se han impartido cursos que abordan temas relacionados con situaciones problemáticas específicas, tales como: gestión y conservación ambiental, desarrollo comunal, mercadeo y contabilidad para microempresarias, entre otros. Estos cursos se han diseñado y aplicado a solicitud de grupos de líderes de comunidades rurales.

En resumen, el compromiso de la Escuela de Sociología y su misión fundamental ha sido la preparación de profesionales capaces, críticos y comprometidos con la realidad de su tiempo, el fomento del saber, la investigación científica y la acción social. No obstante, el 
mayor reto es mantener ese rumbo, superar las debilidades y orientar su camino con principios $y$ lineamientos estratégicos claros.

\subsection{RETOS Y PERSPECTIVAS DE LA SOCIOLOGÍA EN CENTROAMÉRICA ${ }^{5}$}

La ruta de la Sociología en Costa Rica y Centroamérica marca un arduo y aún inconcluso camino hacia su reconocimiento profesional, social y político como ciencia social con perfil propio. Son muchos los retos y compromisos que la comunidad académica y profesional sociológica debe asumir para orientarse hacia una nueva ruta de la Sociología en Costa Rica y Centroamérica.

\subsubsection{SOCIOLOGÍA EN COSTA RICA Y CENTROAMÉRICA: ALGUNAS DEBILIDADES}

El xII Congreso Centroamericano de Sociología, celebrado en agosto de 2010, en Costa Rica, tuvo como tema central: "Hacia una nueva ruta de la Sociología en Centroamérica: reflexión, análisis y propuesta de integración regional". En el marco de esta temática, se realizó un intenso intercambio y reflexión sobre cómo se pueden fortalecer los vínculos entre las distintas comunidades académicas y profesionales sociológicas en la región, así como, la manera en que la Sociología puede contribuir a desarrollar propuestas de integración regional alternativas que están siendo impulsadas por las élites políticas y empresariales (con énfasis en el libre comercio).

En las mesas dedicadas a la reflexión sobre el estado de la disciplina, se discutió sobre la enseñanza y los retos de la Sociología en Centroamérica, identificándose cuatro aspectos que muestran las principales debilidades de la Sociología en la región.

La primera alude a la escasa presencia de académicos de la región, tanto en los foros como en los intercambios internacionales. Según el autor Rovira Mas:

... en los congresos y actividades de la International Sociological Association

5 Algunos contenidos de este apartado han sido obtenidos de Alvarado y Villena, 2011.
(Isa) se puede corroborar una escasa presencia de sociólogos latinoamericanos, africanos, asiáticos (con la excepción de los de India) y del Medio Oriente, en relación con la cantidad que asiste desde las sociedades centrales del sistema mundial. Otra manifestación consiste en la intensa referencia cruzada que se hacen entre sí los autores e investigadores de las sociedades del Norte en sus publicaciones (2000: 2).

Además, existe una muy escasa participación de académicos centroamericanos en eventos de alcance latinoamericano, como los congresos de aLAS $y$ LASA, pero también una escasa participación a nivel institucional en las redes regionales como cLacso.

En segundo lugar, derivado de lo anterior, no se cuenta con una comunidad académica profesional de alcance mundial: en la comunidad de profesionales en Sociología, no se ha realizado un esfuerzo constante $y$ sistemático orientado a atesorar, procesar y aprovechar críticamente, el patrimonio que generaciones de profesionales e investigadores han producido sobre la realidad centroamericana, lo que a la vez ha inhibido la posibilidad de desarrollar suficientes enfoques teóricos que se derivan de esta herencia para la adecuada interpretación de Centroamérica como objeto de análisis.

Como una tercera debilidad se puede mencionar el ámbito centroamericano, la desigualdad en los procesos de institucionalización (se puede añadir también de profesionalización), así como, la debilidad de los vínculos entre nuestras sociólogas y sociólogos.

También, es posible señalar que el desigual desarrollo de la institucionalización $y$ la profesionalización en los distintos países de la región, se da en varias dimensiones, comenzando con la relativa a la enseñanza de la Sociología a nivel de grado y posgrado, existiendo una precariedad institucional en varios países de la región, como es el caso de Nicaragua y El Salvador, donde la enseñanza de la Sociología se ha visto amenazada por la posibilidad de cierre de las respectivas carreras 
en las universidades públicas o privadas. En ese sentido, es sin duda Costa Rica, el país que tiene una institucionalidad académica más consolidada, con dos carreras de Sociología en universidades públicas (la Universidad de Costa Rica y la Universidad Nacional), así como, un programa de posgrado (la Maestría Centroamericana en Sociología, en la UcR).

Como cuarta debilidad existe un intercambio regional incipiente, sobre todo en el ámbito universitario, pese a existir una organización regional, el Consejo Superior Universitario de Centroamérica (csuca) el cual sobre todo en la década de los 70 jugó un papel importante en la promoción de vínculos e incluso, en la formulación de algunos proyectos y programas de alcance regional, como la recordada Revista Estudios Sociales Centroamericanos.

En este punto, probablemente, es FLAcso la institución con mayor alcance regional, con sus tres unidades académicas (Costa Rica, El Salvador y Guatemala), además de llevar adelante algunos importantes proyectos de investigación de alcance regional, entre los que sin duda destaca la monumental "Historia general de Centroamérica", publicado en seis tomos durante la primera mitad de la década de los años 90 . Además, ha establecido un programa de posgrado en Ciencias Sociales (Maestría y Doctorado) de carácter centroamericano, que posee una publicación periódica de carácter académico, la Revista Centroamericana de Ciencias Sociales.

Ante tales debilidades, el Dr. Sergio Villena Fiengo hace referencia a algunos desafíos que debe enfrentar la comunidad sociológica de la región, sobre todo en su dimensión académica universitaria:

i) La relación entre compromiso social y rigor académico (que implica la relación entre la academia y la calle); ii) La relación entre teoría y metodología (que implica también la relación entre docencia e investigación); iii) La relación entre disciplina e interdisciplina; iv) La relación entre función crítica, rigor académico y ejercicio profesional (2010: 15).

La discusión iniciada en el Congreso de ACAS (2010), ha avanzado y se ha orientado a la propuesta de algunos lineamientos de acción estratégica con el propósito de contribuir a consolidar la disciplina en el contexto centroamericano y superar las debilidades antes señaladas.

\subsubsection{POSTULADOS Y LINEAMIENTOS PARA DESARROLLO ESTRATÉGICO DE LA SOCIOLOGÍA}

Con el propósito de fortalecer la legitimidad social de la Sociología como disciplina y como profesión, así como de contribuir al fortalecimiento de la universidad como bien público, potenciando desde esa base a los sectores subalternos y vulnerables para promover un cambio de la sociedad en general, se proponen los siguientes postulados orientadores y líneas de acción:

a) La Sociología está llamada a desempeñar un papel fundamental en la construcción de la universidad como un espacio público de pensamiento crítico y producción de conocimiento no sujeto a las exigencias mercantiles.

b) La Sociología debe contribuir a fortalecer la legitimidad de la universidad pública mediante acciones orientadas al desarrollo de una ecología de los saberes como puntal de la justicia epistémica y la construcción participativa de conocimiento científicamente riguroso y socialmente útil, acorde con una racionalidad material emancipatoria.

c) La Sociología requiere generar condiciones institucionales, epistemológicas y pedagógicas [andragógicas] para la formación de profesionales $y$ la producción de conocimiento académicamente riguroso y socialmente útil, fortaleciendo la investigación-acción, la acción social y la ecología de saberes.

d) La Sociología tiene que proyectarse hacia aquellas zonas $y$ regiones que presentan mayores problemas en términos de desarrollo y son las que proveen una menor cantidad de estudiantes que ingresan a la educación universitaria (Alvarado y Villena, 2011). 
Los lineamientos propuestos deben servir para materializar la reflexión en el diseño de propuestas que promuevan el desarrollo estratégico de la Sociología, fortalezcan su ejercicio profesional y fundamentalmente, potencien su impacto social, evidenciando con mayor fuerza el carácter democrático de la organización que la representa a nivel gremial: el Colegio de Profesionales en Sociología de Costa Rica.

Mediante un trabajo conjunto se debe apoyar una vinculación efectiva del Colegio con las escuelas de Sociología, con el fin de promover la disciplina y apoyar el ejercicio profesional de la Sociología en las mejores condiciones, así como, la formación de redes de intercambio, encuentros, pasantías y movilidad docente $y$ estudiantil, además, la efectiva participación en los congresos de Sociología organizados a nivel nacional, regional y mundial. Todo esto con la meta de superar las debilidades, haciendo efectivos los postulados y lineamientos para el desarrollo estratégico de la Sociología en Costa Rica.

\section{EL COLEGIO DE PROFESIONALES EN SOCIOLOGÍA Y SU RELACION CON LA DEMOCRACIA EN COSTA RICA}

En este artículo se abarcó el tema del desarrollo de la Sociología como disciplina científica, así como, su influencia y presencia en la sociedad, condición indispensable para fundamentar la relación del Colegio de Profesionales en Sociología con la democracia en Costa Rica. No sería posible argumentar sobre el rol e incidencia de esta organización profesional en los procesos democráticos, sin la existencia y aporte de la entidad que le da sentido a su vida: la Sociología como ciencia y como profesión.

A pesar del camino recorrido y de los aportes de la Sociología a la sociedad costarricense, la lucha de distinguidos sociólogos y sociólogas por crear el Colegio de Sociología tuvo que enfrentar muchos obstáculos. Lo que era un proyecto obvio en el proceso de institucionalización de la disciplina, tuvo que esperar 44 años desde la constitución de la primera carrera de Sociología, para que las iniciativas y esfuerzos fructificaran en el año 2011, con la creación del Colegio de Profesionales en Sociología de Costa Rica, sancionado mediante Ley nro. 8974.
El surgimiento del Colegio debe considerarse como un hito sobresaliente en el proceso de consolidación de la disciplina y de la práctica sociológica en Costa Rica. Basta con leer la Ley que lo crea, para entender la absoluta autonomía e independencia en su funcionamiento, condición contundente de su intrínseca naturaleza democratizadora, que tiene fundamento en el artículo $1^{\circ}$ de la Constitución Política de Costa Rica.

Hablar de democracia es abrir la puerta a una profunda discusión desde tiempos antiguos y es uno de los conceptos más polémicos, situación comprensible pues se alude al poder, a la justicia, la igualdad, la desigualdad, a la distribución, al derecho positivo y al derecho humano. El concepto de democracia toca aspectos tan profundos y sensibles que algunos autores en su análisis incluyen a la dignidad personal como categoría para medir justicia distributiva. No es este el espacio para abordar esta histórica polémica; sin embargo, es necesario un breve esbozo que permita hacer relación al fundamento democrático del Colegio.

El dilema de siempre en las democracias representativas es la dificultad para distinguir qué es del interés del ciudadano y qué es del interés particular del aspirante al puesto de representación ciudadana.

No existe garantía de que las preferencias e intereses de los ciudadanos sean atendidas. El dilema se representa en la imposibilidad de expresión de intereses y preferencias, dificultades en hacer oír su voz y limitaciones de acceso a información sobre la cual basar las decisiones de los ciudadanos, en los procesos electorales tradicionales. Es de conocimiento popular la existencia de gobiernos formalmente reconocidos como democráticos por la opinión mundial, alabados por los organismos y medios de comunicación internacionales, pero con sociedades sustantivamente injustas, en términos de desigualdad; la relación entre justicia y democracia no es transparente, no existe una correspondencia directa entre ambas. Sin duda este tema toca aspectos sensibles de la vida humana $y$ de innegable competencia de la Sociología. Es por esto que, sin pretender abordar un análisis conceptual propiamente dicho, 
sí es importante su relación con el papel del Colegio de Profesionales en Sociología en Costa Rica.

Se ha hecho referencia a su impacto social y por tanto, su relación con el conocimiento de la realidad, de los fenómenos fundamentales, esenciales de la vida humana. El aporte al conocimiento objetivo de dichos fenómenos es un aporte a la verdad, a la información, que significa poder para transformar $y$ provocar procesos de democratización en la sociedad, siendo parte del compromiso científico y ético de la Sociología, el cual debe ser tutelado y garantizado por el Colegio (así está sancionado en la Ley y en sus objetivos).

De alguna manera, el Colegio es una de las organizaciones que está encomendada a garantizar que las preferencias e intereses de los ciudadanos sean atendidas y que sus voces sean escuchadas, posibilitando el acceso a la información, sobre la cual basar sus decisiones $y$ hacer valer sus derechos. Es un mecanismo para tratar de resolver el dilema de las democracias representativas antes planteado, convirtiéndose en un acercamiento a la democracia entendida en sentido comunal. Lo que Dowrkin propone como una teoría de la acción colectiva: “... se refiere a que colectivamente se realizan acciones que ningún individuo por su cuenta podría hacer, por lo que debemos reconocer unidades de acción en las que el actor es necesariamente colectivo" (Dowrkin, 1990, citado en Liaudat, 2011: 2).

Es este el papel del Colegio, el de actor colectivo; su quehacer emerge como un acción colectiva de carácter comunal: "en el sentido de que requiere que los individuos actúen como parte de un grupo asumiendo su existencia como tal" (Liaudat, 2011: 2).

Ese carácter comunal confiere una responsabilidad colectiva e imprime una responsabilidad ética a los colegiados en su desempeño como profesionales; una mala praxis compromete la acción individual, pero afecta y desacredita al grupo profesional. Es por eso que el sentido democrático del Colegio no se explica exclusivamente, en la potestad que le confiere la Ley, sino que deviene de la responsabilidad de una acción colectiva comunitaria en el sentido ético. Acción comunitaria monolítica, dice Liaudat (2011), pues existe una unidad de responsabilidad colectiva $y$ una unidad de juicio individual, debido a que en esta organización, la acción individual se define como parte de un grupo: el Colegio.

Si bien, el Colegio es una organización creada por Ley desde la Asamblea Legislativa - primer poder de la República- este no depende ni está sujeto al gobierno, no está inhibido a oponerse a disposiciones del Poder Ejecutivo; al contrario, podría lograr que estas sean derogadas mediante el Poder Judicial o la presión política promoviendo y organizando la movilización social. Esto muestra un ente creado por Ley de la República, pero con autonomía e independencia, que se fundamenta en el artículo 25 de la misma Constitución Política de Costa Rica, al establecer el derecho genérico a la libertad de asociación para fines lícitos.

$\mathrm{Su}$ inherente contenido democrático se encuentra en la esencia misma de lo que conceptualmente se conoce como democracia; es decir, desde la democracia representativa, en articulación con los contenidos de la democracia participativa, así como en la conjugación de los contenidos de estos dos conceptos que se expresa en la democracia distributiva. En el caso analizado, implica la protección de los derechos ciudadanos por parte del Estado, lo cual se confiere también a los colegios profesionales, que en el caso del CPScR, se materializa en el Capítulo II de la Ley de la República nro. 8974, atribuyéndole al Colegio las siguientes funciones:

Capítulo II, artículo 2:

a) Estimular el progreso de la Sociología y, con el concurso de sus respectivos colegios profesionales, de otras disciplinas afines.

b) Promover la superación integral de sus miembros, así como estimular las investigaciones de carácter profesional.

c) Velar por el cumplimiento de los principios éticos y legales en el ejercicio de la profesión.

d) Defender los derechos de sus miembros y gestionar o acordar, cuando sea posible, los auxilios que estime necesarios para proteger a sus colegiados. 
e) Promover, en forma dinámica, la contribución de la profesión en la aplicación en asuntos de interés público; para ello, nombrará comisiones permanentes de análisis y estudio de los problemas nacionales.

f) Pronunciarse sobre los problemas de interés nacional e internacional relacionados con los objetivos $y$ las actividades profesionales del Colegio.

g) Promover el intercambio científico entre sus miembros $y$ entre otros profesionales del país $y$ del extranjero $y$, en especial, contribuir con la realización de los propósitos de integración profesional centroamericana.

h) Cooperar con las universidades y los centros de educación superior en el desarrollo de la Sociología y de las otras disciplinas sociales afines que así lo soliciten.

Emitir opinión y brindar asesoramiento a los poderes del Estado, los organismos, las asociaciones y las instituciones públicas y privadas, en materia de competencia del Colegio, cuando así lo soliciten (Ley de Creación del Colegio de Profesionales en Sociología de Costa Rica, nro. 8974. Asamblea Legislativa de la República de Costa Rica. La Gaceta nro. 188, viernes 30 de setiembre de 2011).

Lo anterior significa que el Estado, por medio de la Ley de Creación, encomienda al Colegio de Profesionales en Sociología de Costa Rica, la protección de los ciudadanos, le confiere la responsabilidad de garantizar la honestidad e idoneidad de los servicios profesionales que se brindan al público en el campo de la Sociología y le asigna la tarea de emitir opinión y brindar asesoramiento a los poderes del Estado, a las instituciones y organizaciones públicas $y$ privadas, en materia de competencia del Colegio. Aquí hace relación la misión del cPscr con la democracia. Seguidamente, se fundamenta esto con base en el análisis de Velásquez y Liaudat.

Cuando se habla de democracia, se puede imaginar: "Gobierno del pueblo". Santiago Liaudat analiza el aporte conceptual de Ronald Dworkin (Liaudat, 2011: 4), interpretando la democracia como un sistema de gobierno en donde los intereses de los individuos se expresan en las acciones gubernamentales, expresión que se hace posible por medio del mecanismo del voto $y$ se materializa mediante estructuras representativas en el gobierno, supone entonces el gobierno de las mayorías. Este modelo hace referencia a la democracia representativa.

Por su parte, Karina Velásquez (2011) en su ensayo sobre democracia, interpretando a Habermas hace referencia a la sociedad civil como:

La sociedad organizada. Constituye un espacio de actuación claramente diferenciado respecto del aparato estatal $y$ del mercado, está formada por asociaciones civiles voluntarias e instituciones independientes (las universidades, los colegios profesionales, las organizaciones no gubernamentales, las comunidades religiosas, organizaciones sociales de base, etc.). Es creada por los propios ciudadanos a través de luchas y movilizaciones. La función de estas asociaciones consiste en articular corrientes de opinión pública, de actuación y deliberación ciudadana que permitan hacer valer las voces de los ciudadanos ante el Estado en materia de reivindicación de derechos y políticas públicas. Ellas buscan configurar espacios públicos de vigilancia contra la concentración ilegal del poder político (y económico). La autonomía es el rasgo característico de la sociedad civil (2011: 5).

Esta es la misión del CPscr y el propósito para el cual fue creado. En efecto, según lo expuesto por Velásquez, el Estado costarricense le asigna un rol esencial a esta organización profesional, al ser creada con fines públicos, característica que le otorga un importante papel en el fortalecimiento de la democracia. En este sentido, la Contraloría General de la República en el dictamen C-253-2008, indica que:

Los colegios profesionales son corporaciones de Derecho Público, en las cuales el Estado delega la vigilancia y disciplina de una determinada profesión. Estos 
colegios ejercen funciones públicas, las cuales esencialmente consisten en la regulación de la práctica profesional de sus agremiados, y el ejercicio del poder de policía. Así las cosas, tenemos que los colegios profesionales se caracterizan porque ejercen potestades disciplinarias sobre sus miembros, así como porque tienen el deber de velar por el adecuado ejercicio profesional.

No cabe duda de que el CPScR ejerce funciones de carácter público, siendo potestades de imperio delegadas por el Estado en el marco del sistema democrático de nuestro país, siempre en estricto apego a la ley que lo rige. Al respecto, la Sala Constitucional de la Corte Suprema de Justicia indica que:

En este orden de ideas, el requisito en cuestión es consecuencia del poder fiscalizador que posee el Estado en aras del bien común, el cual podría ser ejercido en forma directa o bien, como en el caso de nuestro país, delegarlo en forma exclusiva en una organización no estatal - Colegio Profesional-, pues intereses superiores a los particulares de los administrados exigen que exista un control sobre la actividad que realiza un grupo determinado de profesionales por constituir su actividad un servicio público cumplido a través de sujetos particulares (Voto 5583-1995).

De acuerdo con Velásquez (2011), el Colegio es creado por los propios ciudadanos a través de luchas y movilizaciones, su función consiste en hacer valer los derechos de sus agremiados, articular corrientes de opinión pública, de actuación y deliberación ciudadana que permitan poner en valor las voces de los ciudadanos ante el Estado, en materia de reivindicación de derechos y políticas públicas. Además, busca configurar espacios públicos de vigilancia contra la concentración ilegal del poder. Se destaca la autonomía como rasgo característico de esta organización en la sociedad civil en la que se desenvuelve.
Semejante propósito solo ha sido posible mediante la estrategia de trabajo que se ha puesto en práctica durante la gestión del Colegio: el trabajo en equipo. En este caso se habla concretamente de la Junta Directiva, concebida como un conjunto de personas que interactúan entre sí y con otros individuos, su trabajo voluntario está orientado a fines comunes en busca del bien común. Se asumen compromisos individuales dentro de una racionalidad colectiva.

El trabajo de la Junta Directiva se basa en los principios de la participación democrática, respeto, delegación con confianza, evaluación participativa y corrección oportuna. Esto hace realidad el lema que dice que: "no es suficiente con tener ideas democráticas. Lo más importante es actuar democráticamente".

El legislador Dr. Alberto Salom Echeverría, proponente del proyecto de creación del Colegio, entre sus muchas argumentaciones expresa:

La Sociología es una profesión relativamente nueva, aun cuando el cultivo sistemático de sus conocimientos $y$ prácticas se remonta al siglo xviII. El desarrollo del conocimiento sobre el comportamiento social se ha convertido en una actividad de gran importancia para el normal funcionamiento de las sociedades contemporáneas.

La Sociología ha cultivado parcelas importantes de conocimiento, que se asocian con la formación y el funcionamiento de grupos, sectores o clases sociales $y$ familias, con las relaciones más estructurales que constituyen usos, costumbres e instituciones sociales, $y$ con espacios de ese comportamiento asociados a las relaciones de poder, a las relaciones culturales, a las vías y medios de comunicación e integración social, entre otros.

Este conocimiento ha adquirido relevancia pública por la capacidad de generar futuros escenarios de la sociedad para el corto, mediano y largo plazos, o previsiones con grados estimables de precisión 
sobre el comportamiento de los actores y agentes en los espacios de las relaciones sociales abordadas por estas profesiones. Sirve para descomponer los fenómenos sociales observados, en categorías inteligibles $y$ formular relaciones entre ellas, que permiten proponer hipótesis coherentes sobre los orígenes o determinantes de esos fenómenos, y la forma en que se desarrolla su dinámica. La posibilidad de comprender esos procesos $y$, por tanto, la de poder influir en ellos, entraña el ejercicio de un conocimiento que tiene implicaciones sociales y públicas. La aplicación práctica de este conocimiento, así como, desde luego, su cultivo y acrecentamiento, han venido adquiriendo últimamente gran importancia en distintos ámbitos del quehacer social, entre ellos el comercial, el político, el industrial y el de la comunicación colectiva.

Por ello, un grupo de profesionales en Sociología ha creído conveniente crear un colegio profesional, que sirva a los fines del desarrollo del conocimiento en los campos que favorezcan el bien común nacional, proteja y regule la aplicación de ese conocimiento con reglas de buen comportamiento profesional, ético $y$ moral, $y$ sirva de interlocutor general entre el gremio, los poderes públicos y la sociedad costarricense general. Por lo anterior, someto a la consideración de las señoras diputadas y los señores diputados el siguiente proyecto de ley (Proyecto de Creación del Colegio de Profesionales en Sociología de Costa Rica).

Es así como la Ley se aprueba el 6 de julio de 2011 y se publica en La Gaceta el 30 de setiembre de 2011. Este hecho histórico fundamenta y posiciona la importancia de las organizaciones de profesionales en Sociología, en los procesos de fortalecimiento de la democracia en América Latina.

Otro aspecto a destacar es que lo establecido en la Ley, se confirma y se operacionaliza en el correspondiente reglamento, el cual se aprobó como Decreto Ejecutivo nro. 38129 del Ministerio de la Presidencia y fue publicado en La Gaceta nro. 35 del 19 de febrero de 2014.

En síntesis, con la creación del Colegio de Profesionales en Sociología de Costa Rica, se cumple con el objetivo de la creación de los colegios profesionales como impulsores de la democracia, la justicia y la inclusión social, así como, como propulsores del desarrollo humano y la paz, en la realización de actividades tanto dentro del sector público como dentro del sector privado, dado que estas agrupaciones representan una importante fuerza económica y social (Estrada, 2011: 1).

Como asociación profesional, el cPScR está en capacidad de coadyuvar en la lucha contra la corrupción, especialmente, en el sector público que tanto contribuye a la desigualdad social, a la vez que socaba las bases democráticas del país al obstaculizar la democracia participativa $y$ distributiva. Ello se logra a través de los principios éticos que lo rigen, los cuales le permiten exigir el mismo comportamiento a los sectores gobernantes, reclamando ética y transparencia en sus acciones.

Si los distintos profesionales que colaboran con el gobierno están colegiados, es de esperarse que sus acciones sean asumida con ética y responsabilidad, tal y como lo establece el Código de Ética de sus correspondientes colegios profesionales, bajo cuyos principios han sido juramentados.

\section{COMENTARIO FINAL}

El proceso de consolidación de la Sociología como disciplina científica y como carrera profesional, así como, su presencia y aporte al desarrollo social, es condición consustancial en la explicación del rol del Colegio de Profesionales en Sociología dentro de la democracia costarricense.

El aporte de la Sociología en los procesos de enseñanza-aprendizaje que se llevan a cabo en la academia, el ejercicio profesional de las sociólogas y los sociólogos en el mercado laboral y la función que la Ley le confiere al Colegio "... como ente público no estatal con personalidad jurídica y patrimonio propio" (Ley nro. 8974, 2011), le otorga al cPscR la posibilidad 
de influir en los procesos democráticos, como ente de carácter gremial y organización respaldada por una disciplina de probada presencia e influencia societal.

A través del desarrollo del presente artículo, se ha tratado de argumentar ese papel fundamental que cumple el Colegio de Profesionales en Sociología de Costa Rica.

\section{BIBLIOGRAFÍA}

Alvarado Vargas, Asdrúbal y Camacho Monge, Daniel. "Presencia de la Escuela de Sociología de la Universidad de Costa Rica en la sociedad". Revista Reflexiones 1 (89). Universidad de Costa Rica, 2011.

Alvarado Vargas, Asdrúbal y Villena Fiengo, Sergio. "La nueva ruta de la Sociología en Centroamérica: retos y perspectivas". Revista Centroamericana de Ciencias Sociales 2 (8). 2011: 105-121.

Arán Córtes, R. "Desarrollo social y Bachillerato en Sociología, Universidad de Costa Rica (1950-1978)". [Tesis de Licenciatura en Sociología]. San José, Costa Rica: Universidad de Costa Rica, 1995.

Camacho, Daniel. "Treinta y cinco años de evolución de la Teoría de Desarrollo en las Ciencias Sociales en América Latina (1974-2009)". Conferencia Inaugural de la Facultad de Ciencias Sociales en el marco del 35 aniversario. Inédito. San José, Costa Rica: Universidad de Costa Rica, 2009.

Chinchilla Coto, J.C. "El quehacer del sociólogo en la Costa Rica de la década de los noventa”. Cuadernos de Sociología 2. Escuela de Antropología y Sociología, Universidad de Costa Rica, 1993.

Darat, Nicole. "Emancipación y democracia: una relectura de la justicia distributiva". Astrolabio Revista Internacional de Filosofía 11. Universidad de Barcelona, 2010. En: <http://www.raco.cat/ index.php/Astrolabio/article/view/ 239018/321276>.

De Souza Santos, B. Presupuestación participativa hacia una democracia redistributiva. 1998. En: <http://www. boaventuradesousasantos.pt/media/ Presupuestacion\%20Participativa_ Ruralter.pdf>.

Escuela de Sociología de la Universidad de Costa Rica (ucR). Propuesta de reforma del Plan de Estudios de Bachillerato en Sociología. Documento de trabajo, 2011.

Estrada, Carlos. El papel de los profesionales en la consecución del desarrollo humano y la paz en sus países y a nivel mundial. 2011: 1-13. En: <http://asiapacifico. edu.mx/index.php?option = com content\&view $=$ article \&id=238:el-papelde-los-profesionales-en-la-consecuciondel-desarrollo-humano-y-la-paz-en-suspaises-y-a-nivel-mundial-autor-carlosr-estrada-e\&catid=17:ponencias \& Itemid=48>.

Liaudat, Santiago. "Democracia comunal y justicia distributiva en Ronald Dworkin". viI Jornadas de Investigación en Filosofía. La Plata, Argentina, 27 al 29 de abril de 2011. En: <http://www.memoria. fahce.unlp.edu.ar/trab_eventos/ ev.1296/ ev.1296.pdf>.

Li Kam, Sui Moy. "Desarrollo de la Sociología académica en Costa Rica". Serie Contribuciones del Instituto de Investigaciones Sociales 5. Universidad de Costa Rica, 1990.

Mallo, Susana. "Democracia, ciudadanía y participación: nuevos sujetos sociales". Serie Ponencias del Taller Pt 01/10. Grupo Interdisciplinario Estado, Sociedad y Economía en los siglos xx $y$ xxi (giese 2021) de la Universidad de la República, 2010. En: <http://www.ccee. edu.uy/extension/grupo_soc_estado_ec/ PT0110SM.pdf>.

Pereira, G. "Justicia distributiva, eticidad democrática y ciudadanía". Revista Internacional de Filosofía Política 29. Universidad de la República, 2007: 113-137. En:<https://www.academia. edu/178891/Justicia_distributiva_ eticidad_democratica_y_ciudadania $>$.

Ramírez Guier, Gustavo. "Una interpretación histórica de la evolución de las Ciencias Sociales en Costa Rica”. Revista de 
Ciencias Sociales 33. Universidad de Costa Rica, 1986: 93-105.

Reuben Soto, Sergio. "Notas sobre la contribución de la Escuela de Antropología y Sociología a la interpretación de la realidad social costarricense". Revista Reflexiones 82. Universidad de Costa Rica, 2003.

Rodríguez Solera, C. "Problemas y opciones de la Sociología costarricense contemporánea". Anuario de Estudios Centroamericanos 18 (1). Universidad de Costa Rica, 1992: 51-59.

Rovira Mas, Jorge. "El docente universitario: una perspectiva desde la Sociología". Serie Contribuciones del Instituto de Investigaciones Sociales 23. Universidad de Costa Rica, 1995.

Rovira Mas, Jorge. "Los orígenes de la sociología como una ciencia social en Costa Rica y la contribución de Eugenio Fonseca”. Eugenio Fonseca Tortós. Selección de su obra sociológica. Fernando Bolaños, Jorge Rovira Mas y José Luis Vega (eds.). San José, Costa Rica. Editorial Universidad Estatal a Distancia-Editorial Universidad de Costa Rica (EUNED-EuCR), 2000: 864-867.

Rovira Mas, Jorge. "El desarrollo de la sociología en Centroamérica: la promesa incumplida". Iconos Revista de Ciencias Sociales 30. Facultad Latinoamericana de Ciencias Sociales (flacso) Sede Ecuador, 2008.

Rovira Mas, Jorge y Mora Alfaro, Jorge. "Sociedad y Sociología en América Central: hacia un programa de investigación sobre cultura política, Estado y políticas públicas". Anuario de Estudios Centroamericanos 16 (1). Universidad de Costa Rica, 1990: 111-132.
Sala Constitucional de la Corte Suprema de Justicia. Voto nro. 5583. 1995.

Torres-Rivas, Edelberto. "Acerca del pesimismo en ciencias sociales". Centroamérica: entre revoluciones $y$ democracia. Colección Pensamiento Crítico Latinoamericano. clacso Coediciones, 2008: 249-281.

Torres-Rivas, Edelberto. "Las múltiples crisis de la sociología latinoamericana". Cuadernos de Sociología. Universidad de Costa Rica, s.f.

Velásquez, Karina. Justicia distributiva, democracia y liberalismo. 04 de diciembre de 2011. En: <http://blog.pucp. edu.pe/item/148906/justicia-distributivademocracia-y-liberalismo>.

Villasante, T. "De la democracia delegada distributiva a las democracias participativas conversacionales". Reparto: Presupuestos Participativos y Autogestionados en Las Cabezas de San Juan. Sevilla, España: Atrapasueños, 2003. En: <http://www.ucm.es/info/ eurotheo/hismat/materiales $>$.

Villena, S. "La formación profesional en Sociología en América Latina: historia y desafíos actuales". хा Congreso Centroamericano de Sociología. Inédito. San José, Costa Rica, 2010.

Wing-Ching Sandí, Isabel. "La Universidad de Costa Rica: crisol de las ciencias del hombre". Revista de Ciencias Sociales 64. Universidad de Costa Rica, 1994: 81-40.

Fecha de ingreso: 25/06/2014

Fecha de aprobación: 04/07/2014 
